\title{
PHOTOPHYSICAL PROPERTIES OF THE DCM AND DFSBO STYRYL DYES CONSEQUENCE FOR THEIR LASER PROPERTIES
}

\author{
JEAN-CLAUDE MIALOCQ and MARTINE MEYER \\ CEA CEN/Saclay, IRDI/DESICP/DLPC/SCM/URA 331 CNRS, \\ F-91191 Gif-sur-Yvette Cédex, France
}

(Received 5 October, 1989; in final form 30 November 1989)

\begin{abstract}
The two styryl dyes, 4-dicyanomethylene-2-methyl-6-p-dimethylaminostyryl-4H-pyran (DCM) and 7dimethylamino-3-( $p$-formylstyryl)-1, 4-benzoxazin-2-one (DFSBO) exhibit similar solvent-induced shifts of their absorption and emission spectra related to a large intramolecular charge transfer (ICT) in the first singlet excited state. From the Stokes shift values $\left(v_{A}-v_{F}\right)$ and a vectorial analysis of their ground state dipole moment ( $\mu_{g}=6.1 \mathrm{D}$ for DCM and 5.8 D for DFSBO), and using the Lippert-Mataga theory, we have estimated the dipole moments of their fluorescent excited states $S_{1}\left(\mu_{e}=26.3 \mathrm{D}\right.$ for DCM and 27.6 D for DFSBO). Intersystem crossing to the triplet state is totally inefficient in DCM but significant in DFSBO. Moreover the absorption of the DFSBO triplet is quite large in the emission band $(600-650 \mathrm{~nm})$, which makes of DFSBO a poor laser dye. Although DCM trans-cis photoisomerization can be quite efficient in non polar solvents (chloroform, tetrahydrofuran), DFSBO does not photoisomerize probably due to steric hindrance and to the $S_{1}$ character which should be more "benzoxazinone" than ethylenic. DFSBO is also shown to exhibit rotamerism.
\end{abstract}

\section{INTRODUCTION}

The two styryl dye molecules, 4-dicyanomethylene-2-methyl-6-p-dimethylaminostyryl-4H-pyran (DCM) and 7-dimethyl-amino-3-( -formylstyryl)-1,4-benzoxazin-2one (DFSBO) have very similar absorption spectrum maxima in the $450-500 \mathrm{~nm}$ range which depend strongly on the solvent polarity. It was interesting to compare their photophysical and photochemical properties since DCM is a widely used laser dye $^{1,2}$ because of its broad tunability and high conversion efficiency under flashlamp, ${ }^{3,4} \mathrm{XeCl},{ }^{5}$ argon ion laser, ${ }^{6}$ second harmonic output of a Q-switched Nd: YAG laser ${ }^{7,8}$ and copper vapor laser ${ }^{9,10}$ pumping. DCM spectral properties are remarkable as regards the weak overlap between the absorption spectrum and the emission spectrum, i.e. to the large Stokes shift $\left(v_{A}-v_{F}\right)^{3}$ which is also valuable in luminescent solar concentrators. ${ }^{11-14}$ The DCM spectral shift of the absorption and fluorescence spectra with solvent polarity ${ }^{15-23}$ is related to the intramolecular charge transfer due to the presence of an electron donor group and an electron acceptor group on each side of the ethylenic bond. ${ }^{24}$ In a preliminary study, ${ }^{18}$ we have determined the dipole moment increase upon DCM electronic excitation using the DCM Stokes shift values $v_{A}-v_{F}$ ) in 25 solvents and the Lippert-Mataga theory: ${ }^{25-28}$ 
$\mu_{e}-\mu_{g}=20.2 \mathrm{D}$. A vectorial analysis enabled us to estimate the DCM ground state dipole moment $\mu_{g}=6.1 \mathrm{D}$ and thus that of the DCM fluorescent singlet state $\mu_{e}=$ 26.3 D. ${ }^{18}$ More recently in an attempt to describe fully the photophysical properties of DCM and the surprising monoexponential behaviour of the fluorescence decay obtained in time correlated single photon counting (TCSPC) experiments with nanosecond flashlamp excitation, ${ }^{15,16}$ we undertook TCSPC measurements using tunable picosecond laser pulse excitation. ${ }^{20,21,23}$ They clearly showed the existence of a trans-cis equilibrium in various solvents under ambient light, in good agreement with the findings of Drake et al., who were able to identify the two photoisomers using high performance liquid chromatography (HPLC) and nuclear magnetic resonance spectroscopy (NMR). ${ }^{15,17}$ We thus found that the nonradiative deactivation is governed by two competing processes, $S_{1} \longrightarrow S_{0}$ internal conversion (ic) to the ground state and $S_{1} \longrightarrow P^{*} \longrightarrow$ cis photoisomerization $\left(P^{*}\right.$ is the perpendicular excited state). We found that the efficiency of the latter decreases in more polar solvents as due to the lowering of the $S_{1}$ zwitterionic potential energy surface which creates a double well potential model and a higher energy barrier to isomerization..$^{23,29-32}$ Our results thus substantiate the theoretical model of Salem et al. ${ }^{29-32}$ who took into account the suggestion of Wulfman and Kumei ${ }^{33}$ that the presence of any electron-attracting or repelling ion, molecule or group near either end of the double bond will cause more highly polarizable perpendicular ${ }^{1} A_{1}(Z)$ and ${ }^{1} B_{2}$ (v) excited singlet states of alkenes, according to the symmetry designations of Mulliken $^{34}$ and Kaldor-Shavitt. ${ }^{35}$ The doubly excited state ${ }^{1} A_{1}(Z)$ is replaced by a low energy $S_{2}$ state in the Orlandi-Siebrand model of the photoisomerization of stilbene. ${ }^{36}$ According to these authors, in low viscosity solvents, $S_{2}$ relaxes towards the perpendicular configuration and then undergoes internal conversion to $S_{0}$ with an equal chance to relax towards a cis or a trans configuration. This model does not explain the solvent polarity effect on the DCM photoisomerization. Hsing-kang et al. have interpreted their fluorescence data by considering two different intramolecular charge transfer (ICT) states of DCM in dynamic equilibrium: a short wavelength emission was assigned to a planar conformation and a long wavelength emission to a twisted (TICT) conformation. ${ }^{16}$ More recently the fluorescence decay of DCM was found nonexponential in dibutylether $\left(5\right.$ and $\left.-35^{\circ} \mathrm{C}\right)$ and the main fluorescent state was described as a TICT state. 22

We believe that more experiments are needed to clarify the nonradiative processes in DCM: twisting of the dimethylaminogroup, twisting around the double bond, direct internal conversion and solvent relaxation.

The other dye, DFSBO which belongs to the benzoxazinone family also possesses an electron donor group (dimethylamino) and an electron acceptor group (carbonyl). ${ }^{37,38}$ Le Bris et al. have analyzed the shift of the fluorescence spectrum induced by the solvent polarity using the solvent polarity-polarizability parameter $\pi^{*}$ of Taft and Kamlet. ${ }^{37} \mathrm{~A}$ good correlation was found between the wavenumber of the fluorescence maximum and $\pi^{*}$ in aprotic solvents. Despite the small overlap between the absorption spectrum and the emission spectrum and the high fluorescence quantum yield, ${ }^{37}$ DFSBO did not show a high laser yield under $\mathrm{N}_{2}$ laser or $532 \mathrm{~nm}$ pumping. ${ }^{38}$ 
In the present paper in the light of our recent DCM results, ${ }^{23}$ we present some new data on DCM and extend our study to DFSBO. We thus gained a better understanding of the effects of the molecular structure and of the solvent which may help to design suitable styryl dye molecules possessing appropriate photochemical reactivity and laser properties.

\section{EXPERIMENTAL SECTION}

The nanosecond laser absorption spectroscopy setup has already been described. ${ }^{39}$ The DCM and DFSBO triplet states were populated via triplet-triplet energy transfer from naphthalene which was excited by the $4^{\text {th }}$ harmonic of a Q-switched Nd: YAG laser. ${ }^{23}$

Fluorescence decay profiles were obtained using a TCSPC apparatus which has been described elsewhere. ${ }^{20,21,23}$

UV-visible absorption spectra were measured with a Beckman UV 5240 spectrophotometer. Fluorescence spectra were obtained with a Perkin Elmer MPF 66 spectrofluorometer. More recently fluorescence quantum yields were measured with a fully corrected Spex Fluorolog 2F111A spectrofluorometer using an ethanolic solution of rhodamine 101 as a reference. ${ }^{40}$

\section{RESULTS AND DISCUSSION}

\section{Absorption Spectra}

The absorption spectrum and the uncorrected fluorescence spectrum of DFSBO in methanolic solution are given in Figure 1. The absorption spectrum consists of a first electronic transition $S_{0} \longrightarrow S_{1}$ located at $483 \mathrm{~nm}$ and two other electronic transitions

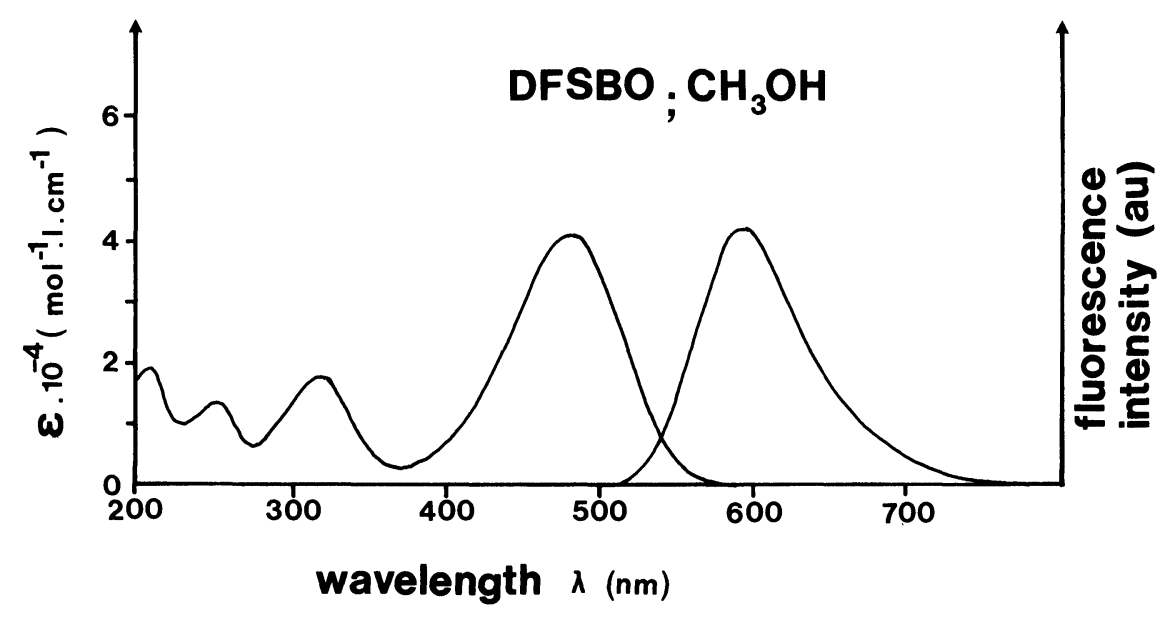

Figure 1 Absorption and fluorescence of DFSBO in methanol. 


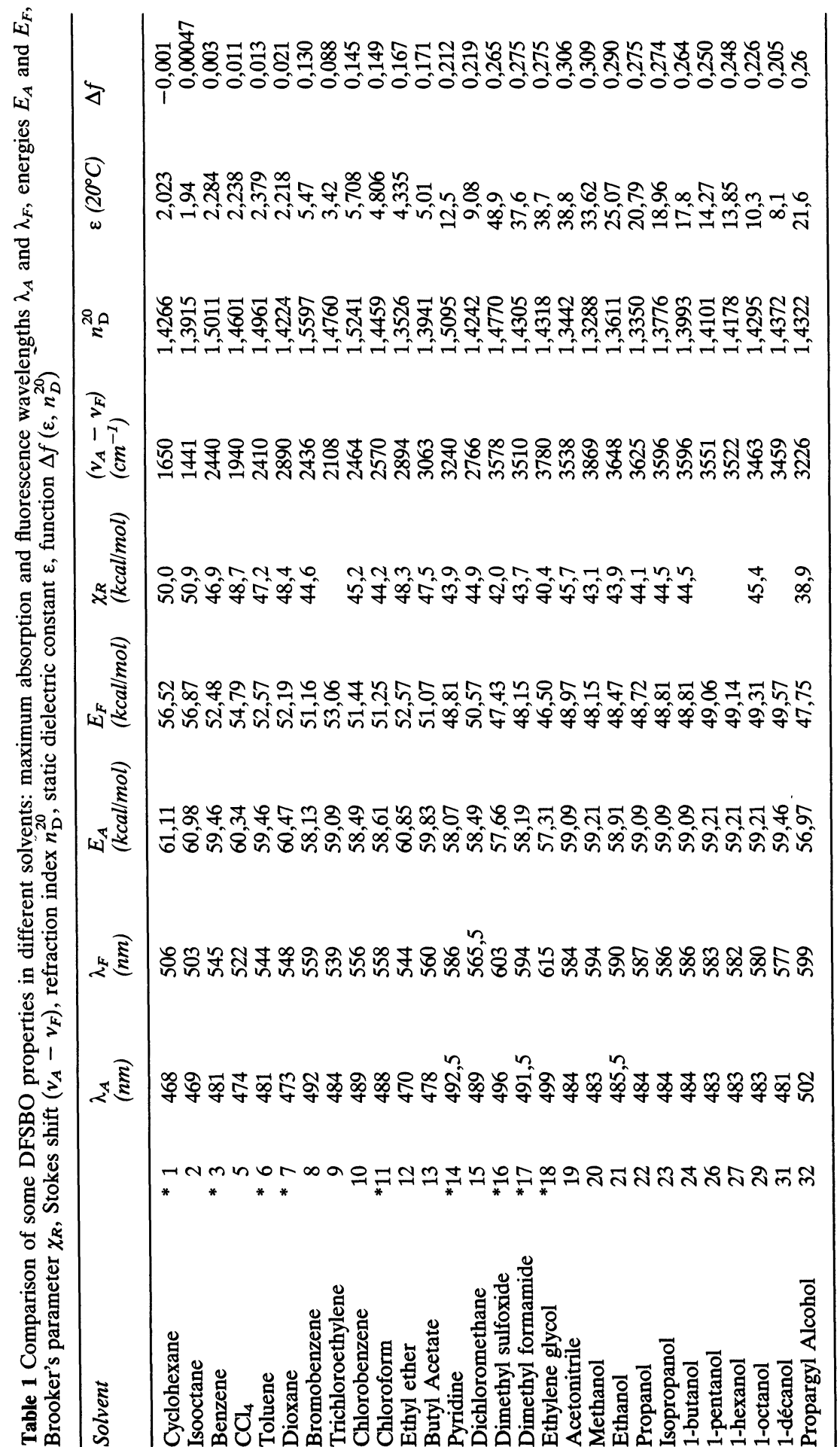




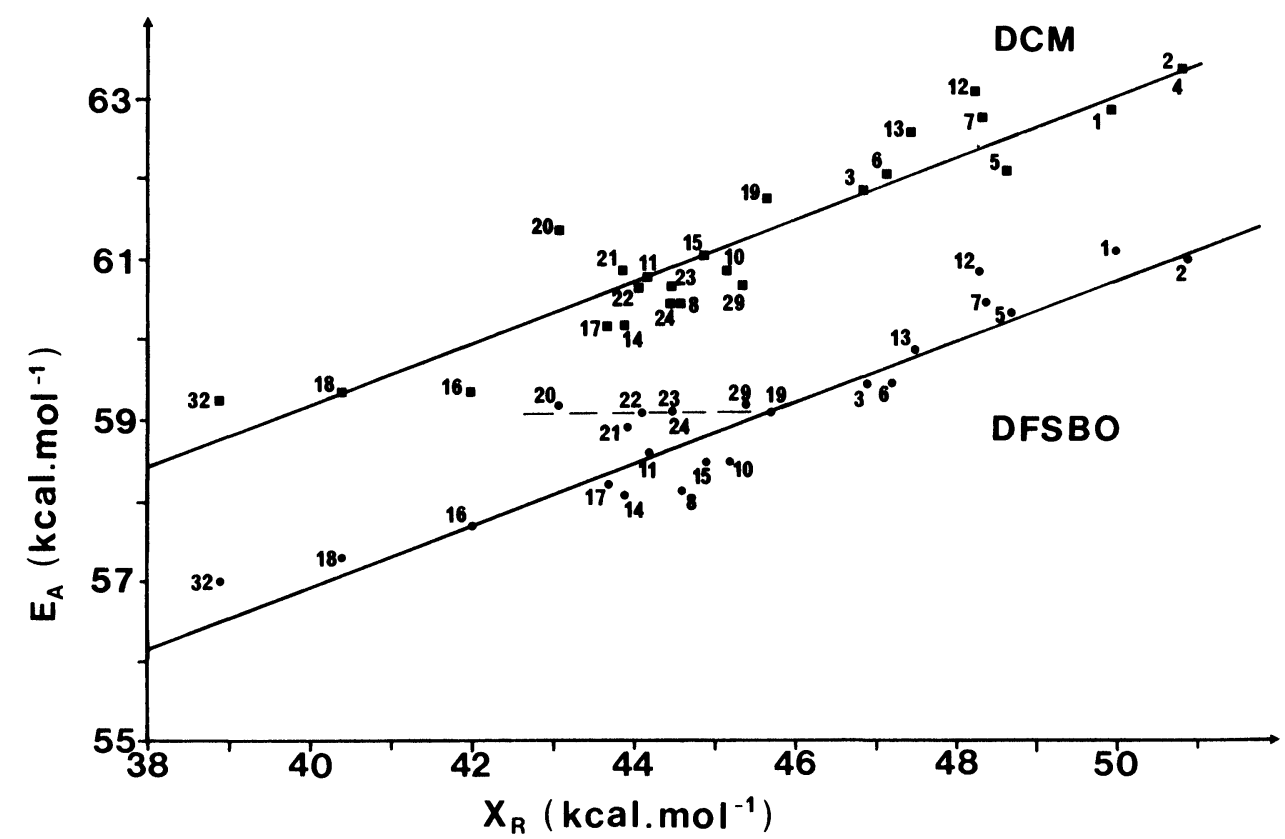

Figure 2 Energies $E_{A}$ of the absorption transitions $S_{0} \longrightarrow S_{1}$ of DCM and DFSBO as a function of the $\chi_{R}$ Brooker's parameter.

at $\sim 320$ and $250 \mathrm{~nm}$ which are well separated from the first one. This behaviour is very different from that met in DCM which presents badly defined absorption bands below $400 \mathrm{~nm} .{ }^{23}$ The DFSBO absorption spectrum is reminiscent of the absorption spectra of homologous benzoxazinone derivatives which do not possess the $p$ formylstyryl group in the 3-position. ${ }^{38}$ Although the DFSBO absorption and fluorescence spectra are largely red-shifted with respect to those of the 3-methylsubstituted benzoxazinone, they indicate that the first excited singlet state $S_{1}$ of DFSBO keeps more benzoxazinone than ethylenic character. Such a behaviour has been already demonstrated in the case of naphthyl and phenanthryl stilbene derivatives. ${ }^{4-46}$ Mazzucato pointed out that the rotation around their ethylenic bridge is thus hindered by high activation energies and resulting low rate constants $k_{t p}$ for the twisting from the trans $(t)$ to the perpendicular $(p)$ configuration. Mazzucatto concluded that choosing the $S_{1}$ energy of a side group was a way to transform a highly photoreactive material in a nonreactive highly fluorescent one. ${ }^{45}$ The energy $E_{\mathrm{A}}$ of the DFSBO absorption maximum (Table 1) correlates excellently with the $\chi_{R}$ solvent property indicator (transition energy of Brooker's merocyanine VII ${ }^{18,47}$ as shown in Table 1 and Figure 2. $\chi_{R}$ is to be used for the red shift of the absorption maximum of weakly polar merocyanine dyes in solvents of increasing polarity. ${ }^{47}$ The plot of $E_{A}$ (in kcal mol ${ }^{-1}$ ) versus the available values of $\chi_{R}$ is a straight line with a correlation coefficient of $0.97 .{ }^{24}$

$$
E_{A}(\mathrm{DFSBO})=0.386 \chi_{R}+41.47
$$


The difference of the $E_{A}$ values in isooctane and propargyl alcohol is 4.0 $\mathrm{kcal} . \mathrm{mol}^{-1}$ in DFSBO, about the same as in $\mathrm{DCM}^{18}$ but much smaller than the one registered by Brooker for merocyanine VII $\left(\Delta \chi_{R}=12 \mathrm{kcal} . \mathrm{mol}^{-1}\right) \cdot{ }^{47}$ In the case of DCM, a similar plot gave ${ }^{18}$

$$
E_{A}(\mathrm{DCM})=0.386 \chi_{R}+43.72
$$

The fact that the slopes are equal is fortuitous but it shows that both dyes absorption spectra behave similarly with respect to the solvent polarity. The observed red shift of the absorption maximum arises from the combination of a blue shift due to the stabilization of the electronic ground state induced by the orientation of the solvent molecules around the solute and a red shift due to the stabilization of the FranckCondon electronic excited singlet state resulting from the electronic polarization of the solvent (dispersion term). Short range interactions such as hydrogen bonding are not taken into account as one can see in Figure 2 for $n$-alcohols (solvents 20-24) which induce a slightly different behaviour. The effect of the solvent electronic polarization can be expressed following the theory based on the reaction field of Onsager that Bayliss applied to merocyanines in apolar solvents. ${ }^{48}$ The plot of the DFSBO transition energy $E_{A}$ (in kcal.mol ${ }^{-1}$ ) versus the $\left(n^{2}-1\right) /\left(2 n^{2}+1\right)$ function of the solvent refractive index in 9 apolar solvents is a straight line with a correlation coefficient of 0.94 (Figure 3)

$$
E_{A}=-60.03 \frac{n^{2}-1}{2 n^{2}+1}+72.84
$$

We have also estimated the effect of the electron acceptor group (CHO) on the absorption transition maximum by calculating in acetonitrile the difference (2.6 $\mathrm{kcal} . \mathrm{mol}^{-1}$ ) between the energies of the absorption transition maxima of DFSBO, $\lambda_{\max }=484 \mathrm{~nm}$, i.e, $E_{A}=59.1 \mathrm{kcal} \mathrm{mol}^{-1}$ (this work) and BOZ-H or 7dimethylamino-3-styryl-1,4-benzoxazin-2-one, $\lambda_{\max }=463 \mathrm{~nm}$, i.e, $E_{A}=61.7 \mathrm{kcal}$. $\mathrm{mol}^{-1}{ }^{49}$ It must be emphasized that the simple picture of a charge transfer from the dimethylamino electron donor group to the formyl electron acceptor end group is not correct since the para-substitution of the styryl by a dimethylamino group gives a compound $\mathrm{BOZ}-\mathrm{NMe}_{2}$ which exhibits a greater red shift of the absorption maximum, $\lambda_{\max }=488 \mathrm{~nm}$, i.e., $E_{A}=58.6 \mathrm{kcal} . \mathrm{mol}^{-1}{ }^{49}$

\section{Fluorescence Spectra}

\section{Pure solvents}

The DFSBO fluorescence spectra are largely red shifted with respect to its absorption spectra. ${ }^{37}$ The wavelengths of the fluorescence maxima $\lambda_{F}$ in 28 solvents are gathered in Table 1, together with the transition energies $E_{F}$, Stokes shift values $\left(v_{A}\right.$ $-v_{F}$ ) (in $\mathrm{cm}^{-1}$ ) and solvent properties, refraction index $n$, static dielectric constant $\epsilon$ and $\Delta f$ values of the Lippert and Mataga theories. ${ }^{25-28,18} \mathrm{~A}$ plot of $\left(v_{A}-v_{F}\right)$ versus $\Delta f$ gives a straight line for solvents $8-32$ in the range $0.09 \leqslant \Delta f \leqslant 0.31$, with a correlation coefficient of 0.93 (Figure 4).

$$
10^{-3}\left(v_{A}-v_{F}\right)=7.43 \Delta f+1.56
$$




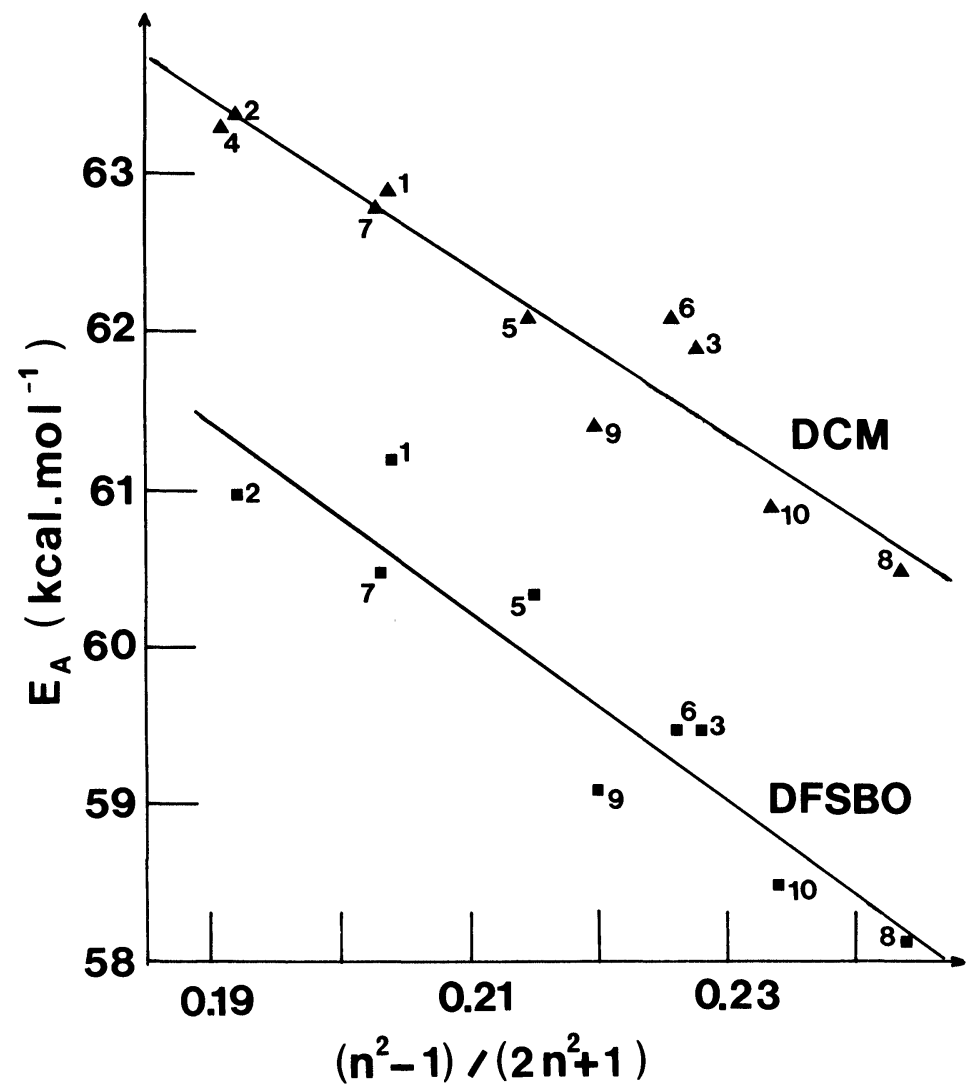

Figure 3 Energy $E_{A}$ of the absorption transition $S_{\mathrm{o}} \longrightarrow S_{1}$ of DCM and DFSBO as a function of $\left(n^{2}-1\right) /\left(2 n^{2}+1\right)$.

The non polar solvents (1-7) must be excluded since according to Lippert some additional terms cannot be neglected in equation (4) when $\varepsilon \sim n^{2}$.

We must confess that the wavelengths of the fluorescence maxima are only average of the values obtained for two excitation wavelengths situated on both sides of the absorption band. We shall see later that the DFSBO fluorescence spectrum depends on the excitation wavelength due to the coexistence of rotamers.

From the slope $m$ of the straight line, we calculated $\left(\mu_{e}-\mu_{g}\right)$ the difference between the dipole moment of the excited state and that of the ground state using equation (5)

$$
m=\frac{2}{h c_{o}} \frac{\left(\mu_{e}-\mu_{g}\right)^{2}}{a^{3}}=7.94 \times 10^{3} \mathrm{~cm}^{-1}
$$

where $a$ is the radius (in $A$ ) of the spherical cavity in Onsager's theory of the reaction field, $h$ is Planck's constant and $C_{\mathrm{o}}$ is the speed of light. With a $\sim 8.6 \mathrm{~A}$, obtained from the estimation of the ellipsoid half long axis, we found $\left(\mu_{e}-\mu_{g}\right)=21.8 \mathrm{D}$. The 


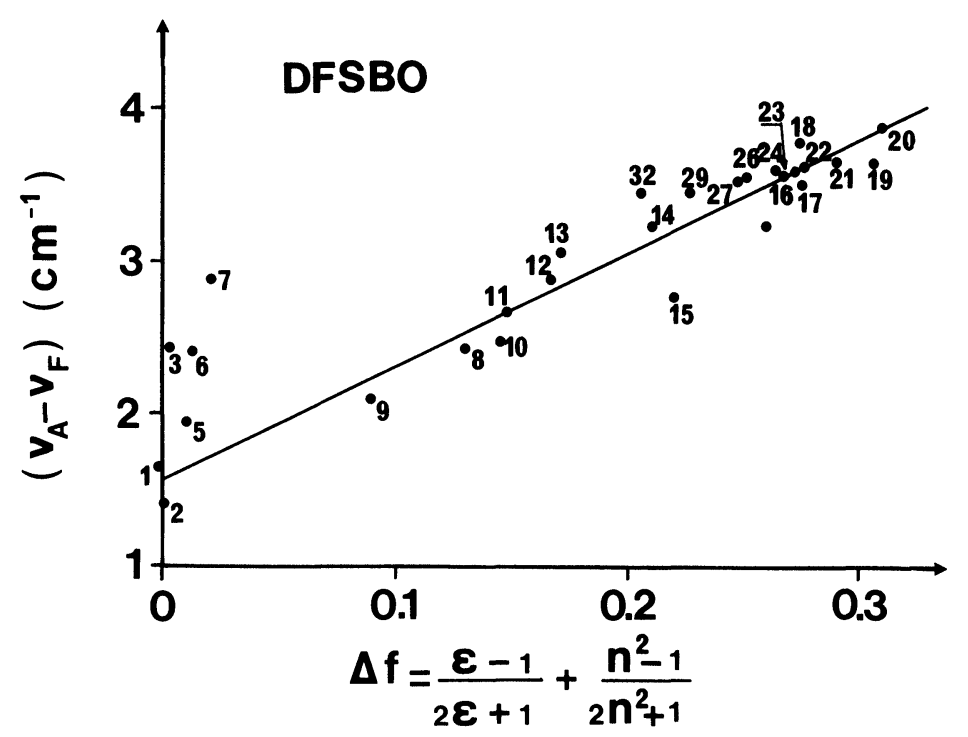

Figure 4 DFSBO Stokes shift $\left(v_{A}-v_{F}\right)$ as a function of $\Delta f$ Lippert's parameter.

DFSBO ground state dipole moment was calculated using a vectorial analysis of the various group dipole moments, ${ }^{18,24} \mu_{G}=5.8 \mathrm{D}$. Therefore $\mu_{e}=27.6 \mathrm{D}$. These values are different from those obtained by Valeur et al. in a PPP (Pariser-ParrPople) calculation $\mu_{g}=8.7 \mathrm{D}$ and $\mu_{e}=20.5 \mathrm{D} .{ }^{50}$ Our experimentally estimated value $\left(\mu_{e}-\mu_{g}\right)$ is thus much higher than the theoretically calculated value $\mu_{e}-\mu_{g}=$ 11.8 D of Valeur et al. A more precise estimation is not possible at the present time.

We however conclude that $\mathrm{DCM}^{18,19,23}$ and DFSBO (this work) both undergo a large intramolecular charge transfer upon excitation in their fluorescent excited state.

\section{Solvent mixtures}

Because of the large shifts of the absorption and fluorescence spectra in increasing polarity solvents, it appeared to us interesting to study the spectral behaviour of DCM and DFSBO in solvent mixtures. We chose methanol-dimethylsulfoxide (DMSO) mixtures since DCM is largely used as a laser dye in both pure solvents. The wavelengths $\lambda_{A}$, the transition energies $E_{A}$ of the maxima of the absorption spectra, the wavelengths $\lambda_{F}$, and the transition energies $E_{F}$ of the maxima of the fluorescence spectra of DCM and DFSBO are gathered in Table 2 together with the volumic percentages of methanol. $E_{A}$ and $E_{F}$ of both dyes are linearly related to the methanol volumic percentages $(X)$ as shown in Figure 5 and Figure 6 . These data indicate that there is no preferential solvation of DCM or DFSBO and that the solvent shell is an homogeneous mixture. Therefore methanol which might induce hydrogen bonding with these solutes does not look like playing a particular role in the binary methanol-DMSO mixtures. 


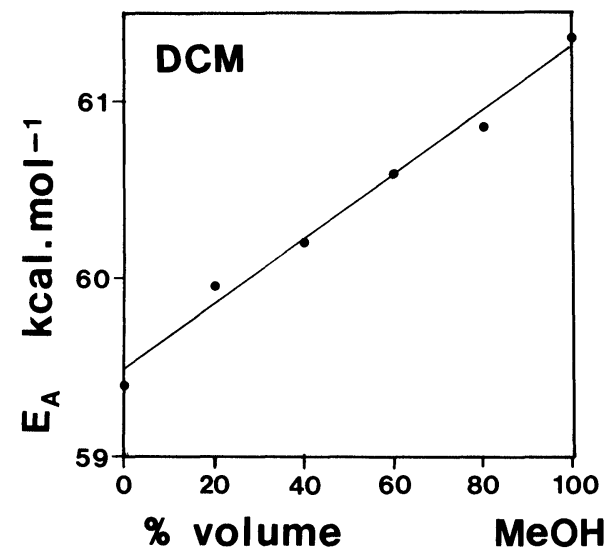

a

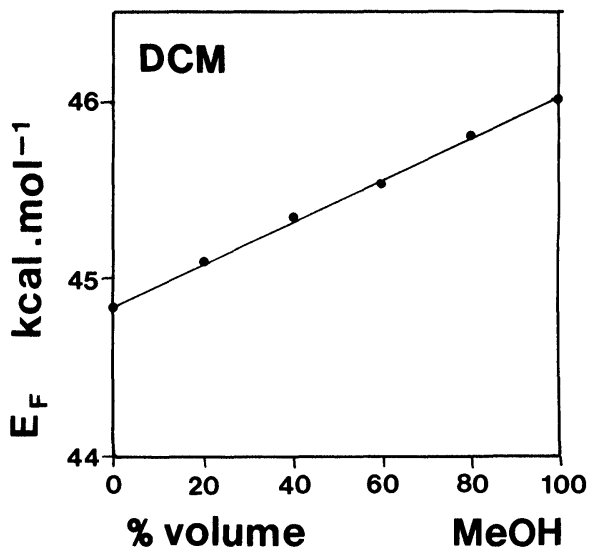

b

Figure 5 Transition energies of DCM as a function of the methanol volumic percentage in methanolDMSO mixtures (a) $E_{A}$ (absorption), (b) $E_{F}$ (fluorescence).

We have also calculated the relative fluorescence yield $R_{F}$ of DCM in these binary mixtures by taking $\Phi^{\mathrm{F}}$ (DMSO) as a reference. $R_{F}$ decays linearly with $X$ according to equation (6) with a correlation coefficient of 0.965

$$
\begin{aligned}
R_{F}= & -0.0036 X+0.953 \\
& 0<X<100
\end{aligned}
$$

Our $R_{F}$ value for DCM in pure methanol $(0.61 \pm 0.06)$ is in good agreement within the uncertainty errors with the ratio $(0.54)$ one can calculate from the DCM

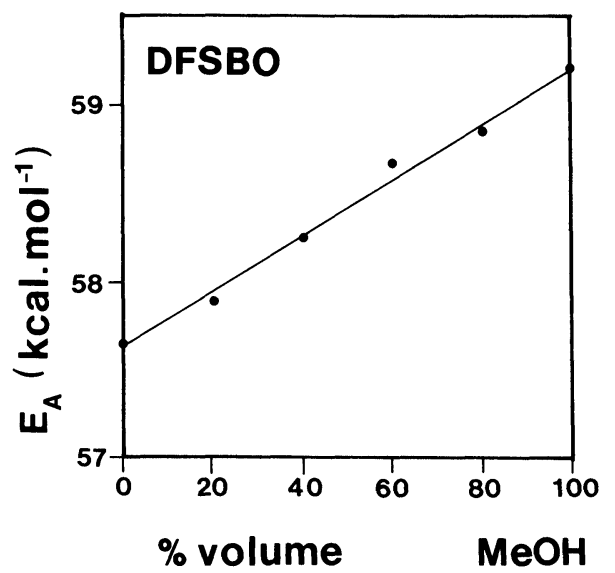

a

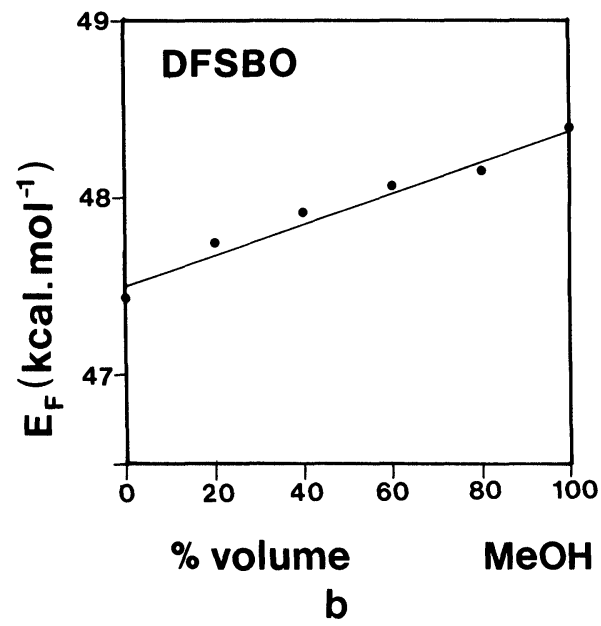

Figure 6 Transition energies of DFSBO as a function of the methanol volumic percentage in methanolDMSO mixtures (a) $E_{A}$ (absorption), (b) $E_{F}$ (fluorescence). 
Table 2 Spectral properties of DCM and DFSBO in binary methanol-DMSO mixtures. Maximum absorption and fluorescence wavelengths $\lambda_{A}$ and $\lambda_{F}$, energies $E_{A}$ and $E_{F}$, relative fluorescence yields $R_{F}$ as a function of the volumic percentage of methanol.

DCM

\begin{tabular}{|c|c|c|c|c|c|}
\hline$\%$ Vol. methanol & $\lambda_{A}(n m)$ & $\lambda_{F}(n m)$ & $E_{A}\left(k_{c a l . m o l}^{-1}\right)$ & $E_{F}\left(k_{c a l . m o l}{ }^{-1}\right)$ & $R_{F}=\begin{array}{c}\Phi_{\text {solvent }} \\
\Phi_{D M S O}\end{array}$ \\
\hline 0 & 482 & 638 & 59.4 & 44.8 & 1 \\
\hline 20 & 477 & 634 & 60.0 & 45.1 & 0.86 \\
\hline 40 & 475 & 630 & 60.2 & 45.4 & 0.75 \\
\hline 60 & 472 & 628 & 60.6 & 45.5 & 0.75 \\
\hline 80 & 470 & 625 & 60.9 & 45.8 & 0.67 \\
\hline 100 & 466 & 622 & 61.4 & 46.0 & 0.61 \\
\hline
\end{tabular}

DFSBO

\begin{tabular}{rllll}
\hline$\%$ Vol. methanol & $\lambda_{A}(\mathrm{~nm})$ & $\lambda_{\mathrm{F}}(\mathrm{nm})$ & $E_{A}\left({\left.\mathrm{kcal} . \mathrm{mol}^{-1}\right)}\right.$ & $E_{F}\left(\mathrm{kcal} . \mathrm{mol}^{-1}\right)$ \\
\hline 0 & 496 & 603 & 57.7 & 47.4 \\
20 & 494 & 599 & 57.9 & 47.8 \\
40 & 491 & 597 & 58.3 & 47.9 \\
60 & 487 & 595 & 58.7 & 48.1 \\
80 & 486 & 594 & 58.9 & 48.2 \\
100 & 483 & 591 & 59.2 & 48.4 \\
\hline
\end{tabular}

fluorescence quantum yields $\Phi^{F}(\mathrm{DMSO})=0.80 \pm 0.05$ and $\Phi^{F}\left(\mathrm{CH}_{3} \mathrm{OH}\right)=0.43 \pm$ 0.08 measured by Drake et al. in $10^{-4} \mathrm{M}$ DCM solutions which contained also cis-isomer. ${ }^{15}$ The $\Phi^{F}$ (DMSO) value given by Hammond is $0.71^{3}$ and the recent value $\Phi^{F}\left(\mathrm{CH}_{3} \mathrm{OH}\right)=0.44 \pm 0.04$ of Valeur $e^{2}$ al..$^{8}$ lead to $R_{F}=(0.62 \pm 0.10)$.

These curves are of a particular interest if by using a solvent mixture one intends to shift the DCM absorption spectrum for a better pumping by a copper vapor laser for example or to get more gain at a particular wavelength in the red.

\section{DFSBO Fluorescence and Excitation Spectra}

As we indicated above, the maxima and the bandwidths (FWHM) of the DFSBO fluorescence spectra depend largely on the excitation wavelength (Table 3). The fluorescence and excitation spectra of DFSBO in butyl acetate solution are given as an example in Figure 7. In non polar solvants, isooctane, $\mathrm{CCl}_{4}$, trichloroethylene, the number and the intensity of well resolved vibronic bands dramatically depend on the observation wavelength. The DFSBO fluorescence spectra in isooctane solution are given in Figure 8a, for two excitation wavelengths 420 and $490 \mathrm{~nm}$. When exciting at $490 \mathrm{~nm}$, the first fluorescence band at $479 \mathrm{~nm}$ completely disappears but the band at $534 \mathrm{~nm}$ increases significantly. The DFSBO excitation and absorption spectra in isooctane solution given in Figure $8 \mathrm{~b}$ and $\mathrm{c}$ show also distinct features. The excitation wavelength dependent fluorescence spectra cannot be interpreted on the basis of "edge-excitation-red-shifts" which are sometimes observed in viscous solvents when the solvent reorientation process is much slower than the emission process. ${ }^{51,52}$ The reorientation time constant of the molecules of the low viscosity solvents under study 
Table 3 DFSBO maximum fluorescence wavelengths $\left(\lambda_{\text {em }}\right)$ and bandwidths (FWHM) observed in various solvents for different excitation wavelengths.

\begin{tabular}{|c|c|c|c|c|}
\hline Solvent & & $\lambda_{e x}(n m)$ & $\lambda_{e m}(n m)$ & $F W H M$ \\
\hline Isooctane & 2 & $\begin{array}{l}420 \\
510\end{array}$ & $\begin{array}{l}479,502,534 \\
502,534\end{array}$ & \\
\hline $\mathrm{CCl}_{4}$ & 5 & $\begin{array}{l}400 \\
460 \\
500\end{array}$ & $\begin{array}{l}502,521,553 \\
502,521,553 \\
521,553\end{array}$ & \\
\hline Bromobenzene & 8 & $\begin{array}{l}450 \\
490 \\
510\end{array}$ & $\begin{array}{l}557 \\
559 \\
560\end{array}$ & $\begin{array}{l}79 \\
77 \\
72\end{array}$ \\
\hline Trichloroethylene & 9 & $\begin{array}{l}420 \\
520\end{array}$ & $\begin{array}{l}512,538 \\
540,575\end{array}$ & \\
\hline Chlorobenzene & 10 & $\begin{array}{l}440 \\
520\end{array}$ & $\begin{array}{l}554 \\
558\end{array}$ & $\begin{array}{l}77 \\
70\end{array}$ \\
\hline Ethyl ether & 12 & $\begin{array}{l}390 \\
530\end{array}$ & $\begin{array}{l}540 \\
547\end{array}$ & $\begin{array}{l}75 \\
72\end{array}$ \\
\hline Butyl Acetate & 13 & $\begin{array}{l}400 \\
530\end{array}$ & $\begin{array}{l}555 \\
568\end{array}$ & $\begin{array}{l}80 \\
74\end{array}$ \\
\hline Dichloromethane & 15 & $\begin{array}{l}430 \\
500 \\
520\end{array}$ & $\begin{array}{l}562 \\
565 \\
569\end{array}$ & $\begin{array}{l}79 \\
75 \\
70\end{array}$ \\
\hline Acetonitrile & 19 & $\begin{array}{l}450 \\
510\end{array}$ & $\begin{array}{l}581 \\
590\end{array}$ & $\begin{array}{l}82 \\
79\end{array}$ \\
\hline Methanol & 20 & $\begin{array}{l}400 \\
550\end{array}$ & $\begin{array}{l}589 \\
598\end{array}$ & $\begin{array}{l}85 \\
76\end{array}$ \\
\hline Ethanol & 21 & $\begin{array}{l}410 \\
540\end{array}$ & $\begin{array}{l}585 \\
593\end{array}$ & $\begin{array}{l}81 \\
78\end{array}$ \\
\hline Propanol & 22 & $\begin{array}{l}420 \\
430 \\
530\end{array}$ & $\begin{array}{l}585 \\
585 \\
593\end{array}$ & $\begin{array}{l}81 \\
85 \\
80\end{array}$ \\
\hline Isopropanol & 23 & $\begin{array}{l}450 \\
520\end{array}$ & $\begin{array}{l}583 \\
590\end{array}$ & $\begin{array}{l}81 \\
79\end{array}$ \\
\hline Butanol & 24 & $\begin{array}{l}440 \\
520\end{array}$ & $\begin{array}{l}582 \\
590\end{array}$ & $\begin{array}{l}82 \\
80\end{array}$ \\
\hline Pentanol & 26 & $\begin{array}{l}470 \\
500\end{array}$ & $\begin{array}{l}581 \\
585\end{array}$ & $\begin{array}{l}82 \\
81\end{array}$ \\
\hline Hexanol & 27 & $\begin{array}{l}450 \\
500\end{array}$ & $\begin{array}{l}579 \\
586\end{array}$ & $\begin{array}{l}82 \\
82\end{array}$ \\
\hline Octanol & 29 & $\begin{array}{l}440 \\
520\end{array}$ & $\begin{array}{l}576 \\
583\end{array}$ & $\begin{array}{l}84 \\
79\end{array}$ \\
\hline Decanol & 31 & $\begin{array}{l}450 \\
500\end{array}$ & $\begin{array}{l}573 \\
580\end{array}$ & $\begin{array}{l}86 \\
84\end{array}$ \\
\hline Propargyl Alcohol & 32 & $\begin{array}{l}440 \\
520\end{array}$ & $\begin{array}{l}598 \\
601\end{array}$ & $\begin{array}{l}81 \\
81\end{array}$ \\
\hline
\end{tabular}

is indeed much shorter $(<100 \mathrm{ps})$ than the fluorescence lifetime which is on the order of one nanosecond. Moreover the observation of different vibronic bands is certainly the best proof that several configurations of DFSBO are involved.

\section{Fluorescence Lifetimes}

The fluorescence lifetimes of DCM measured using the TCSPC apparatus have been published elsewhere. ${ }^{20,21,23}$ Some observed two exponential decays showed that an 


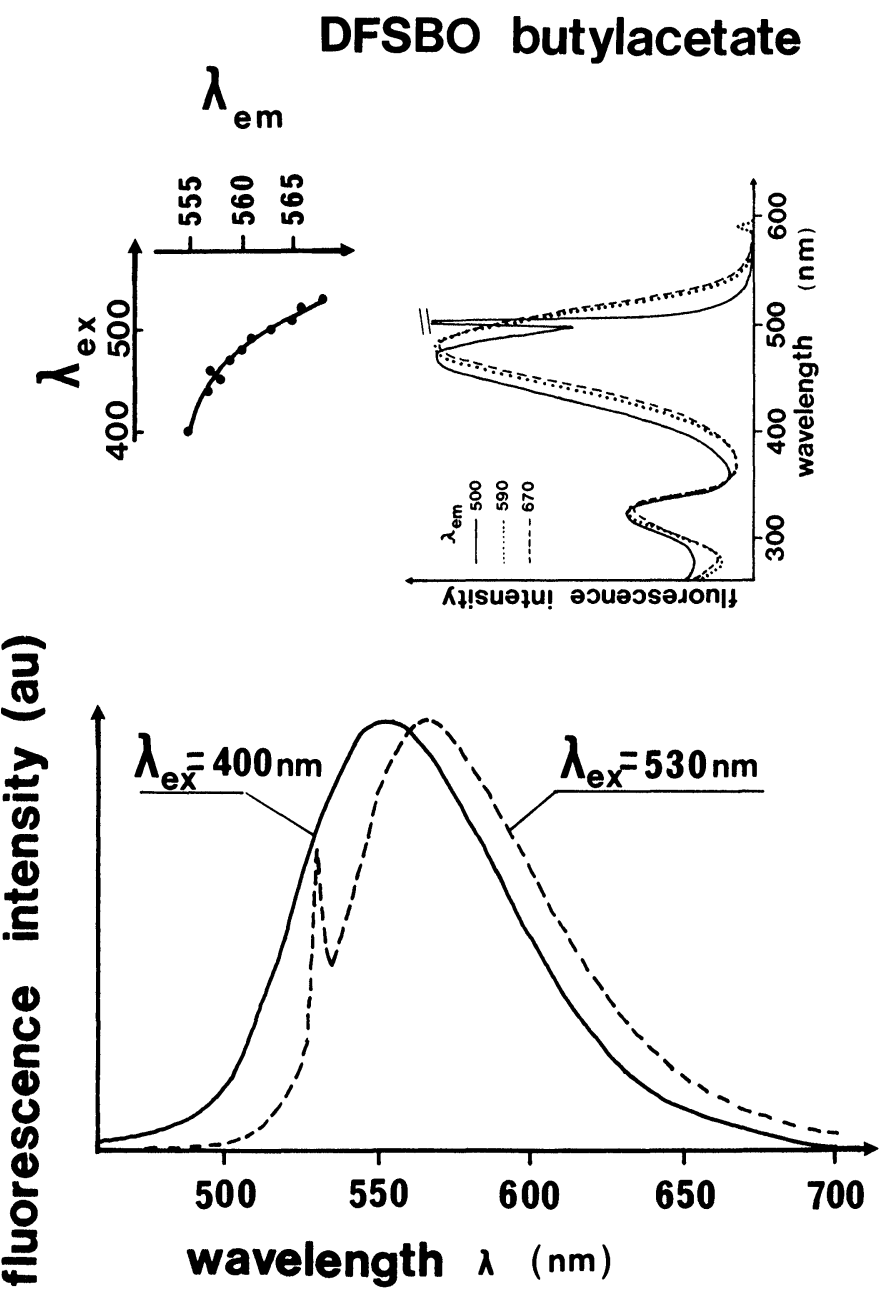

Figure 7 Fluorescence spectra of DFSBO in butylacetate for two excitation wavelengths. On top, excitation spectra for three emission wavelengths.

equilibrium between two trans-cis isomers could be attained very rapidly under room light even in methanol although the photoisomerization quantum yield was very low. For solutions which were freshly prepared and kept in the dark, the DCM decay lifetime was found monoexponential. We recently found in methanol solutions that the monoexponential decay time was depending on the presence of oxygen. In methanolic solutions flushed with argon, the DCM fluorescence decay time was $\tau=$ $(1.41 \pm 0.01) \mathrm{ns}$ but in aerated methanolic solutions, it was $\tau=(1.36 \pm 0.01) \mathrm{ns}^{53}$ in perfect agreement with the value of the trans-isomer fluorescence decay $(1.37 \pm$ 0.01 ) ns obtained in our previous two exponentials decay analysis of room light exposed aerated solutions. ${ }^{21}$ The DCM fluorescence lifetime in methanol is thus shorter than that of DFSBO in ethanol $\tau=2.9 \mathrm{~ns}$ as measured by Le Bris et al. ${ }^{37}$ 
Photostability under Laser Pulse Excitation

The UV-visible absorption spectra of freshly prepared solutions of DFSBO in methanol or DMSO and submitted to laser pulse excitation at $532 \mathrm{~nm}$ indicate a decrease of the absorbance around $490 \mathrm{~nm}$ and $320 \mathrm{~nm}$ and an absorbance increase between 350 and $420 \mathrm{~nm}$. Isosbestic points are found at 317, 353 and $440 \mathrm{~nm}$. The spectral change is found irreversible. In order to understand the nature of the new species formed under light irradiation, we compared the NMR spectra of DFSBO in
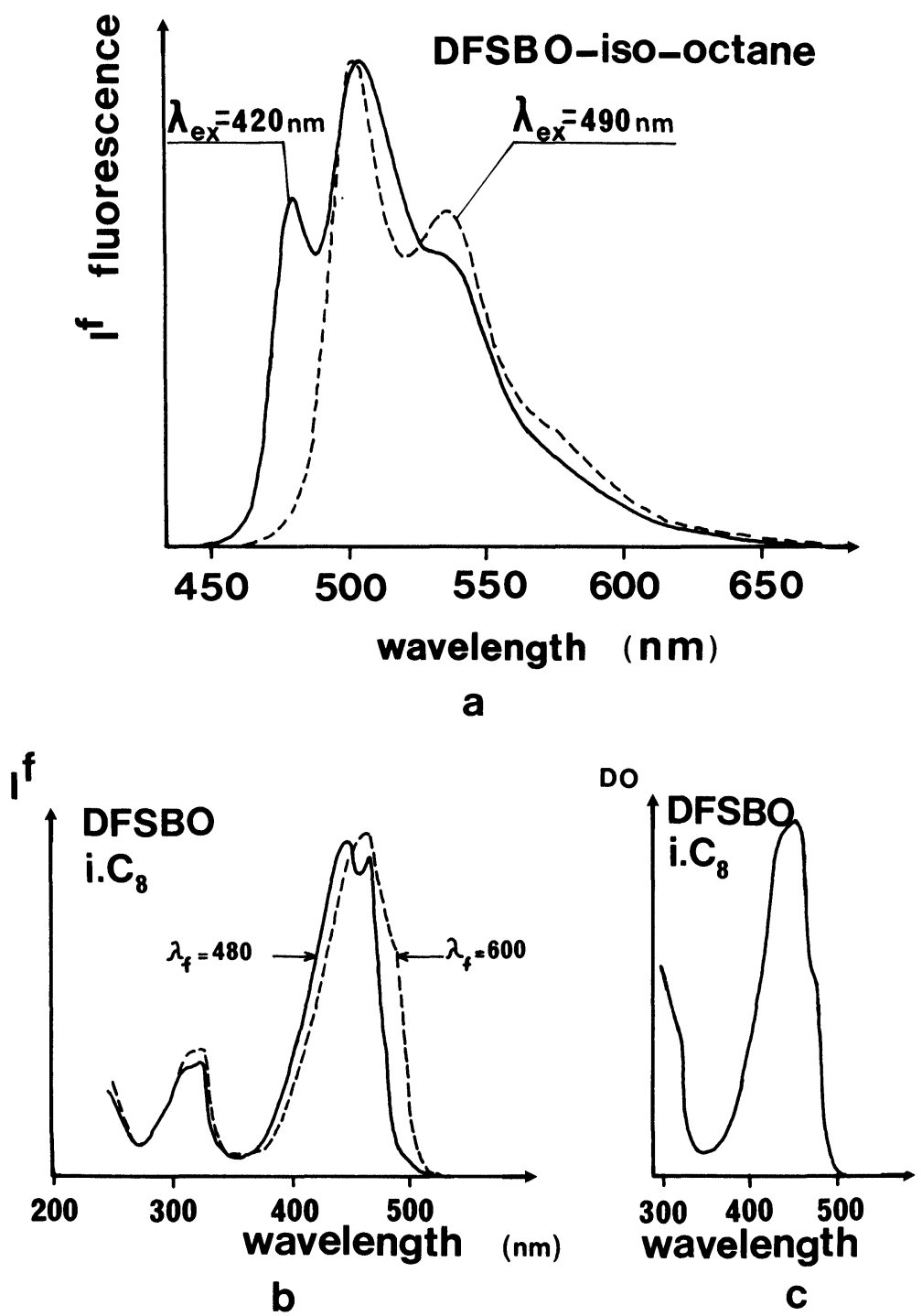

Figure 8 DFSBO-isooctane. (a) Fluorescence spectra for two excitation wavelengths. (b) Excitation spectra for two emission wavelengths. (c) Absorption spectrum. 
deuterated chloroform solutions freshly prepared and kept in the dark to those of solutions submitted to the visible light $(420<\lambda<580 \mathrm{~nm})$ of a xenon arc lamp during three hours. Although new peaks could be observed, they did not present the characteristics of a cis-isomer ${ }^{24}$ as observed in the case of DCM. ${ }^{23}$ Moreover the photostability of solutions flushed with argon was largely improved.

\section{Nanosecond Laser Photolysis}

Absorption spectrum of the first singlet excited state of DFSBO.

The DFSBO excited singlet state generated in $10^{-5}-2 \times 10^{-5} \mathrm{M}$ DFSBO methanolic solutions using nanosecond laser excitation at $532 \mathrm{~nm}$ presented a differential absorption spectrum with a minimum at $480 \mathrm{~nm}$ (photobleaching of the ground state), a maximum around $380 \mathrm{~nm}$ and two isosbestic points at 410 and $~ 515$ $\mathrm{nm}$, as shown in Figure 9. The $S_{1}$ absorbance appeared significant for wavelengths greater than $515 \mathrm{~nm}$ but an accurate determination of the absorption spectrum in this wavelength range was made impossible due to the amplification of the analyzing light in the fluorescence band. After the fast decay of $S_{1}$ within the resolution time of our apparatus $(\sim 5 \mathrm{~ns})$, a transient absorption spectrum remained at $t \sim 200 \mathrm{~ns}$ showing the photobleaching of the ground state absorbance, a wide absorption band around $400 \mathrm{~nm}$ and an isosbestic point at $440 \mathrm{~nm}$. The absorbance change was however very small. The same behaviour was also found in DMSO (Figure 10).

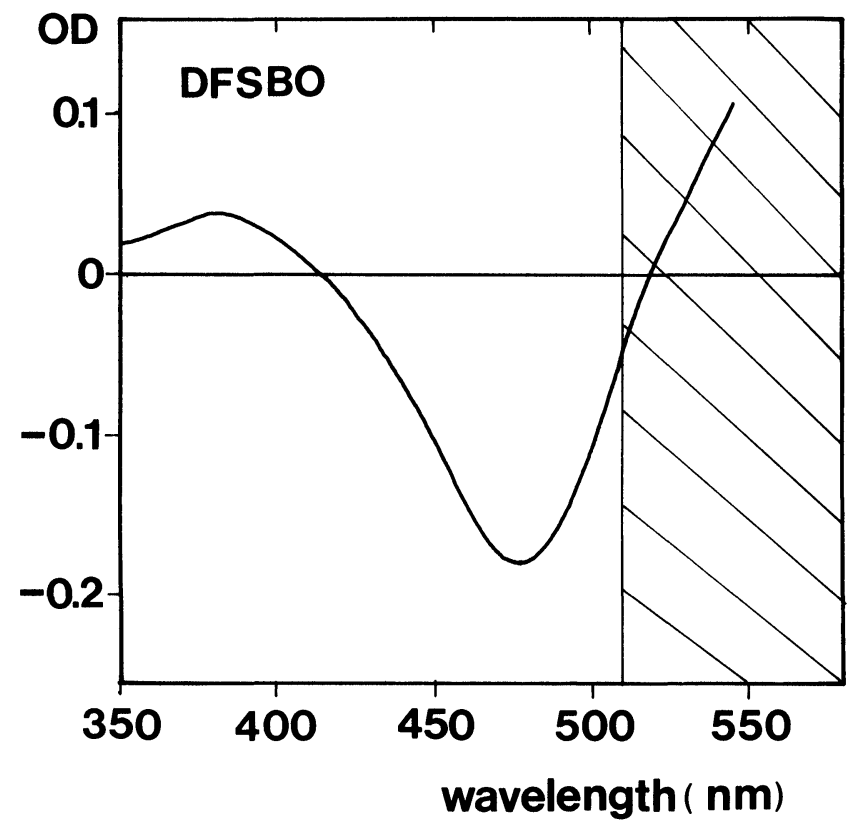

Figure 9 Difference absorption spectrum of the first singlet excited state of DFSBO in methanol. $t \ll 5$ ns. 


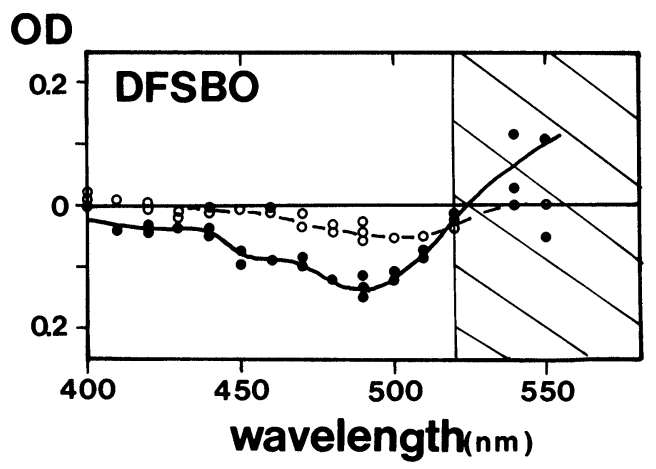

Figure 10 Difference absorption spectra of DFSBO in DMSO. $-\bullet-\bullet t \ll 5 \mathrm{~ns}\left(S_{1}\right)$, $-0-0-0-t=200 \mathrm{~ns}$.

\section{Intersystem crossing to the triplet state}

$532 \mathrm{~nm}$ nanosecond laser excitation of a $10^{-5} \mathrm{M}$ DFSBO methanolic solution flushed with argon gave a significant $650 \mathrm{~nm}$ transient absorbance which disappeared in aerated solution (Figure 11). The difference absorption spectrum presents an absorbance maximum at $660 \mathrm{~nm}$, a large photobleaching at $490 \mathrm{~nm}$ and two isosbestic points at 440 and $535 \mathrm{~nm}$. It decays with a lifetime $\tau=(52 \pm 5) \mu s$. This spectrum was already observed in the nanosecond time range after the $S_{1}$ decay. At $t=400 \mu \mathrm{s}$, a small residual absorbance is observed below $450 \mathrm{~nm}$ and over $530 \mathrm{~nm}$ together with a small photobleaching of the DFSBO ground state absorbance.

In order to ascertain that the $52 \mu$ s lifetime transient absorbance was that of the DFSBO triplet state, we also used naphthalene as a sensitizer in triplet-triplet energy transfer experiments as we did before in the case of DCM. ${ }^{23}$ The kinetics of the energy transfer was analyzed at $480 \mathrm{~nm}$, the wavelength of the absorption maximum of the DFSBO ground state which gave a better signal. The plot of the pseudo first order rate constant $k$ of the DFSBO ground state photobleaching versus the DFSBO

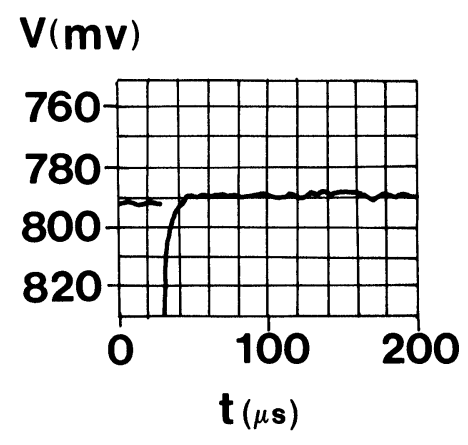

a

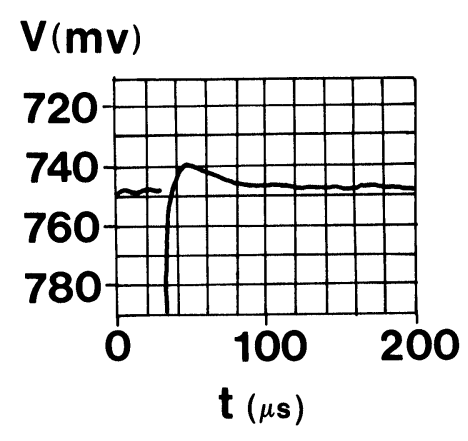

b

Figure 11 Oxygen effect on the $650 \mathrm{~nm}$ transient absorbance of DFSBO in methanol. (a) Aerated solution, (b) Deaerated solution. 
concentration gave the bimolecular second order rate constant $k_{T T}=(2.3 \pm 0.3) \times$ $10^{10} \mathrm{~mol}^{-1} \cdot \mathrm{dm}^{3} \cdot \mathrm{s}^{-1}$. The energy transfer is thus diffusion controlled.

$$
{ }^{3} N+{ }^{1} \mathrm{DFSBO} \stackrel{k_{T T}}{\longrightarrow}{ }^{1} N+{ }^{3} \mathrm{DFSBO}
$$

Using this method we were able to determine the absorption spectrum of the DFSBO triplet state in methanolic solutions containing $1.8 \times 10^{-4} \mathrm{M}$ naphthalene and $2.5 \times$ $10^{-5} \mathrm{M}$ DFSBO. The DFSBO triplet molar extinction coefficient was calculated using the literature molar extinction coefficient of the naphthalene triplet $\varepsilon^{415 \mathrm{~nm}}=4$ $\times 10^{4} \mathrm{~mol}^{-1} \mathrm{dm}^{3} \mathrm{~cm}^{-1}$ and the naphthalene initial triplet absorbance obtained in DFSBO free methanolic solutions containing only naphthalene. We indeed assumed a complete energy transfer since the naphthalene triplet lifetime was respectively 70 and $1.4 \mu \mathrm{s}$ in the absence and in the presence of DFSBO. The DFSBO triplet molar extinction coefficient is thus $\varepsilon_{T}^{660 \mathrm{~mm}}=(5.0 \pm 0.5) 10^{4} \mathrm{~mol}^{-1} \mathrm{dm}^{3} \mathrm{~cm}^{-1}$. The difference absorption spectrum and the calculated absorption spectrum of the DFSBO triplet are given in Figure 12.

The DFSBO intersystem crossing quantum yield $\Phi_{S_{1} \rightarrow T_{1}}$ was then calculated using 3,3'-diethyloxadicarbocyanine iodide (DODCI) as an actinometer. ${ }^{23,54,55}$ DODCI and DFSBO were alternatively excited at $532 \mathrm{~nm}$ in deaerated methanolic solutions which were adjusted to a 0.15 absorbance. We verified that the concentrations of the resulting species, DODCI photoisomer and DFSBO triplet were linear with the laser intensity. The DODCI photoisomer was monitored at $620 \mathrm{~nm}$ $\left([P]=5.1 \times 10^{-7} \mathrm{~mol} . \mathrm{dm}^{-3}\right)$ and the DFSBO triplet at $660 \mathrm{~nm}([T]=(5.6 \pm 1.0)$ $\left.\times 10^{-8} \mathrm{~mol} \cdot \mathrm{dm}^{-3}\right)$. Using the DODCI photoisomerization quantum yield in

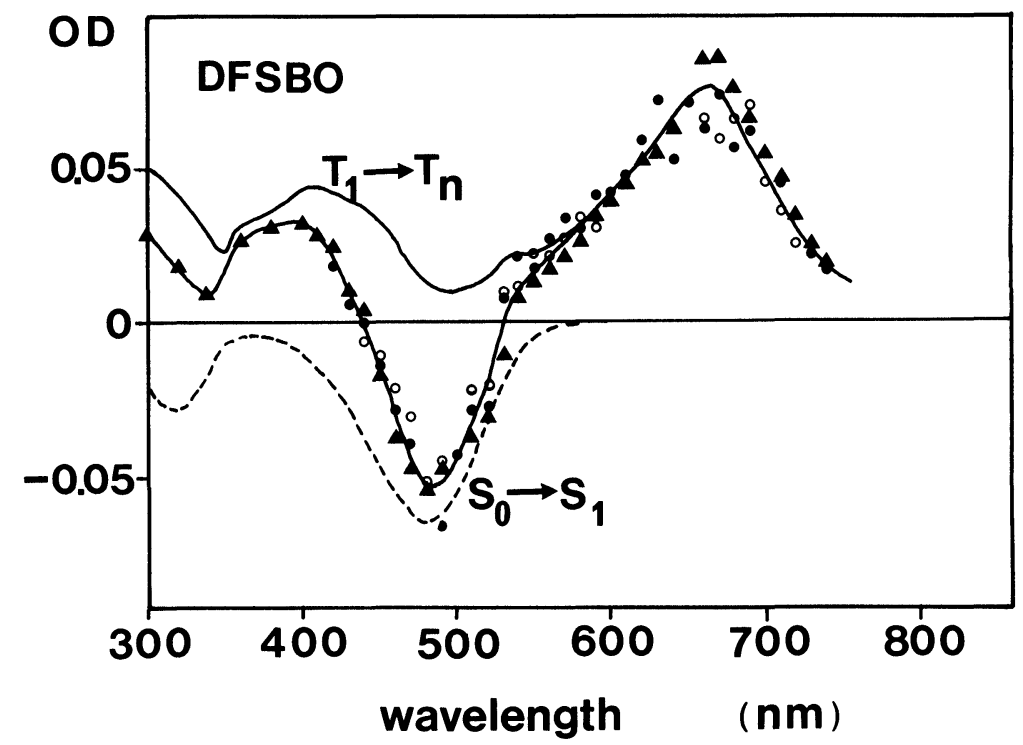

Figure 12 Normalized difference absorption spectra of the DFSBO triplet state in methanol , corresponding photobleaching of the ground state ---- . 
methanol, $\Phi_{p}=0.07,{ }^{56}$ we thus calculated $\Phi_{S_{1} \rightarrow T_{1}}^{\text {DFSBO }}=(8 \pm 2) \cdot 10^{-3}$ which is definitely higher than the DCM estimated upper value $\Phi_{S_{1} \rightarrow T_{1}}^{\mathrm{DCM}} \ll 3 \times 10^{-3} \cdot{ }^{23}$

\section{DCM and DFSBO Photophysical and Photochemical Properties}

Unlike DCM which exhibits a very low quantum yield of intersystem crossing to the triplet state and a low triplet molar extinction coefficient in the $600-650 \mathrm{~nm}$ laser wavelength range, $\varepsilon_{\mathrm{T}, \mathrm{DCM}}^{600-650 \mathrm{~nm}}<10^{4} \mathrm{~mol}^{-1} \cdot \mathrm{dm}^{3} \cdot \mathrm{cm}^{-1}, 23$ DFSBO is characterized by a significantly larger $\Phi_{S_{1} \rightarrow T_{1}}^{\mathrm{DFSBO}}=(8 \pm 2) \times 10^{-3}$ and a more important triplet molar extinction coefficient ${ }_{\text {TDFSBO }}^{600-650 \mathrm{~nm}}>2.5 \times 10^{4} \mathrm{~mol}^{-1} \cdot \mathrm{dm}^{3} \cdot \mathrm{cm}^{-1}$. The build up of a significant DFSBO triplet population under laser pumping will thus reduce the population of the excited singlet state (i.e. the gain) and enhance the absorption losses. ${ }^{57,58}$ Moreover, we found that DFSBO degradates in aerated solutions, probably via chemical reactions involving the triplet state and the excited singlet oxygen ${ }^{1} \mathrm{O}_{2}$

$$
\begin{gathered}
{ }^{3} \mathrm{DFSBO}+{ }^{3} \mathrm{O}_{2} \longrightarrow{ }^{1} \mathrm{DFSBO}+{ }^{1} \mathrm{O}_{2} \\
{ }^{1} \mathrm{O}_{2}+{ }^{1} \mathrm{DFSBO}
\end{gathered}
$$

We did not find any evidence of a trans-cis photoisomerization. Our nanosecond laser absorption studies did not show any absorbance than one may ascribe to a short lived cis-isomer. Moreover, NMR experiments did not show the typical doublet of the ethylenic protons of a stable cis-isomer that we observed in the case of DCM. ${ }^{23}$

Two major reasons may account for the lack of trans.cis photoisomerization. The first one is the trivial steric hindrance that one may expect by inspection of the molecular structure of the cis-isomer. The second one is the nature of the first singlet excited state. We indicated above that it had more benzoxazinone than ethylenic character. This behaviour should enhance the energy barrier for the twisting from the trans to the perpendicular configuration, as pointed out by Mazzucato for other substituted styrenyl compounds. ${ }^{45}$

Now if one considers the "benzoxazinone" character of the first singlet excited state of DFSBO, one must also keep in mind the resonance structures A and B of coumarin derivatives, as pointed out by Drexhage ${ }^{58}$ (Figure 13). In their first excited singlet state $S_{1}$, the polar form B is predominant. The opposite is true in the ground state. A large Stokes shift is thus observed in coumarine derivatives, particularly coumarins substituted by an heterocyclic substituent into the 3-position (coumarin 6, coumarin 30). ${ }^{58}$ As we indicated above, the simple picture of a charge transfer from the dimethylamino group of the benzoxazinone to the formyl end group is not correct

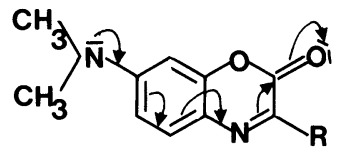

A

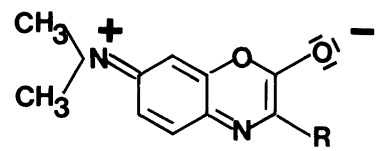

B

Figure 13 Resonance structures of benzoxazinone derivatives. 

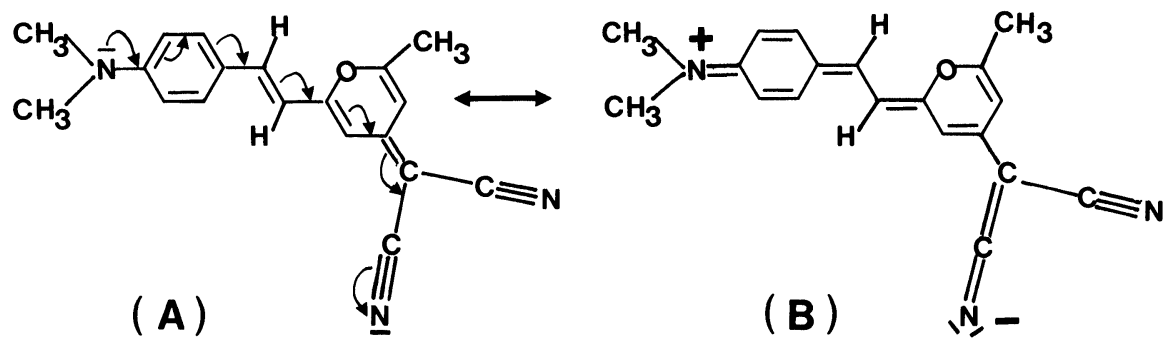

Figure 14 Resonance structures of DCM.

since the para-substitution of the styryl by a dimethylamino group gave an even greater red shift of the absorption maximum. The large Stokes shift of DFSBO has thus a different origin from that of DCM and we conclude that the predominant mesomeric forms of DFSBO and DCM are those represented in Figure 13 and Figure 14.

Let us now come back to the fluorescence and excitation spectra of DFSBO in non viscous solvents. They are dramatically dependent on the observation wavelength. We ascribed the band shifts and the different vibronic bands observed to several configurations of DFSBO. Because we have now rejected the hypothesis of a cis-isomer formation, we believe that these configurations are those of two rotamers resulting from the rotation of the benzoxazinone moiety around the single bond. The occurrence of the rotamers of trans-diarylethylenes is well documented. ${ }^{42-46,59-64}$ The rotamers of compounds which exhibit a variation in the fluorescence spectrum with the excitation wavelength should be almost isoenergetic, ${ }^{63}$ i.e., they must show a similar steric interaction. One of the two DFSBO rotamers might be stabilized by intramolecular hydrogen bonding, as indicated in Figure 15. The mesomeric form (B) (Figure 13) probably favours this intramolecular hydrogen bonding. In many cases a two exponentials decay has been observed in the fluorescence of transdiarylethylenes. ${ }^{42-44,46,61,63,64}$ The existence of rotamers is reinforced by the recent observation of a two exponentials decay in cyclohexane according to very recent experiments of Valeur et al. ${ }^{65}$ Several simultaneous processes including solvent relaxation probably blurred the analysis in more polar solvents.<smiles></smiles>

Figure 15 Planar molecular structures of the DFSBO rotamers. 


\section{CONCLUSION}

Despite the similar behaviour of their absorption and fluorescence spectra in solvents of increasing polarity indicating a large intramolecular charge transfer, the styryl dyes DCM and DFSBO undergo quite different photophysical processes. The nature of the intramolecular charge transfer is different. In DCM the charge is flowing from the dimethylamino end group to the dicyanomethylene end group. In DFSBO, the charge is probably flowing from the dimethylamino end group to the carbonyl group in the 2-position of the benzoxazinone. Intersystem crossing is totally inefficient in DCM but significant in DFSBO. The trans-cis photoisomerization of DCM is efficient in solvents of low polarity (chloroform, tetrahydrofurane) but we have no evidence of a cis-isomer of DFSBO. However, the existence of conformers of DFSBO is clearly demonstrated. They are probably two rotamers resulting from the rotation of the benzoxazinone moiety around the single bond.

We believe that the different behaviour of DFSBO with respect to DCM is related to the "benzoxazinone" rather than ethylenic character of the first singlet excited state of DFSBO.

We have also explained the poor laser action of DFSBO by the significant quantum yield of intersystem crossing to the triplet state and by the high molar extinction coefficient of the triplet state in the emission wavelength range.

\section{Acknowledgement}

The authors are grateful to Prof. B. Valeur (CNAM, Paris) and Dr. D. Doizi (CEN Saclay) for helpful discussions and to Mrs. S. Marguet (CEN Saclay) for her assistance in some of the measurements.

\section{References}

1. F. G. Webster and W. C. McColgin U.S. Patent 3, 852, 683 (Dec. 1974).

2. M. Clerc and J. C. Mialocq, Lasers for Photochemistry, in (Lasers in Polymer Science Technology: Applications, CRC Press). Eds. J. P. Fouassier, J. F. Rabek, 1990, pp. 1-52.

3. P. R. Hammond, Optics Comm. 29, 331 (1979).

4. J. R. Taylor, Optics Comm. 57, 117 (1986).

5. V. S. Antonov and K. L. Hohla, Appl. Phys. B32, 9 (1983).

6. E. G. Marason, Opt. Comm. 37, 56 (1981).

7. C. H. Chen and S. D. Kramer, Appl. Opt. 23, 526 (1984).

8. J. Bourson, D. Doizi, D. Lambert, T. Sacaze and B. Valeur, Opt. Comm. 72, 367 (1989).

9. R. S. Hargrove and T. Kan, IEEE J. Quantum Electron. QE16, 1108 (1980).

10. M. Broyer, J. Chevaleyre, G. Delacrétaz and L. Wöste, Appl. Phys. B35, 31 (1984).

11. J. S. Batchelder, A. H. Zewail and T. Cole, Appl. Opt. 20, 3733 (1981).

12. J. M. Drake, M. L. Lesiecki, J. Sansregret and W. R. L. Thomas, Appl. Opt. 21, 2945 (1982).

13. J. Sansregret, J. M. Drake, W. R. L. Thomas and M. L. Lesiecki, Appl. Opt. 22, 573 (1983).

14. J. Mugnier, Y. Dordet, J. Pouget, M. T. Le Bris and B. Valeur, Solar Energy Materials. 15, 65 (1987).

15. J. M. Drake, M. L. Lesiecki and D. M. Camaioni, Chem. Phys. Lett. 113, 530 (1985).

16. Z. Hsing-kang, M. Ren-Lan, N. Er Pin and G. Chu, J. Photochem. 29, 397 (1985).

17. M. Lesiecki, F. Asmar, J. M. Drake and D. M. Camaioni, J. Lumin, 31-32, 546 (1984).

18. M. Meyer and J. C. Mialocq, Opt. Comm. 64, 264 (1987).

19. M. Meyer and J. C. Mialocq, J. Phys. Coll. C7. Suppl. N. 12, 48, 541 (1987).

20. J. C. Mialocq and M. Meyer, Ultrafast Phenomena VI, Springer Series in Chemical Physics 48, Ed. T. Yajima, K. Yoshihara, C. B. Harris and S. Shinoya, 1988, pp. 559-561.

21. M. Meyer, J. C. Mialocq and M. Rougee, Chem. Phys. Lett. 150, 484 (1988). 
22. W. Rettig and W. Majenz, Chem. Phys. Lett. 154, 335 (1989).

23. M. Meyer, J. C. Mialocq and B. Perly, J. Phys. Chem. 94,98 (1990).

24. M. Meyer, Thèse de Docteur en Sciences, Université de Paris Sud, n` 807, 24 janvier 1989 (CEA-R-5481).

25. E. Lippert, Z. Naturforschung 10a, 541 (1955).

26. E. Lippert, Z. Elektrochemie 61, 962 (1957).

27. N. Mataga, Y. Kaifu and M. Koizumi, Bull. Chem. Soc. Japan 29, 465 (1956).

28. N. Mataga and T. Kubota, Molecular Interactions and Electronic Spectra (Marcel Dekker, New York, 1970), pp. 371.

29. L. Salem and W. D. Stohrer, J. C. S. Chem. Comm. 140 (1975).

30. V. Bonacic-Koutecky, P. Bruckmann, P. Hiberty, J. Koutecky, C. Leforestier and L. Salem, Angew. Chem. Internat. Edit. 14, 575 (1975).

31. L. Salem, C. Leforestier, G. Segal and R. Wetmore, JACS 97, 479 (1975).

32. W. G. Dauben, L. Salem, N. J. Turro, Acc. Chem. Res. 8, 41 (1975).

33. C. E. Wulfman and S. Kumei, Science 172, 1061 (1971).

34. A. J. Merer and R. S. Mulliken, Chem. Rev. 69, 639 (1969).

35. U. Kaldor and I. Shavitt, J. Chem. Phys. 48, 191 (1968).

36. G. Orlandi and W. Siebrand, Chem. Phys. Lett. 30, 352 (1975).

37. M. T. Le Bris, J. Mugnier, J. Bourson and B. Valeur, Chem. Phys. Lett. 106, 124 (1984).

38. F. Dupuy, C. Rullière, M. T. Le Bris and B. Valeur, Opt. Comm. 51, 36 (1984).

39. J. C. Mialocq, Chem. Phys. 73, 107 (1982).

40. T. Karstens, K. Kobs, J. Phys. Chem. 84, 1871 (1980).

41. G. S. Hammond, S. C. Shin and S. P. Van, Mol. Photochem. 1, 89 (1969).

42. J. Saltiel and J. L. Charlton, Rearrangements in ground and excited states, P. de Mayo, Ed. (Academic Press, New York, 1980) Vol. 3, Chap. 14, pp. 25-89.

43. U. Mazzucato, Pure and Appl. Chem. 54, 1705 (1982).

44. G. Bartocci, F. Masetti, U. Mazzucato and G. Marconi, J. Chem. Soc. Faraday Trans. 2, 80, 1093 (1984).

45. G. Mazzucato, Gazzetta Chimica Italiana. 117, 661 (1987).

46. G. Bartocci, F. Masetti, U. Mazzucato, A. Spalletti, I. Baraldi and F. Momicchioli, J. Phys. Chem. 91, 4733 (1987).

47. L. G. S. Brooker, A. C. Craig, D. W. Heseltine, P. W. Jenkins and L. L. Lincoln, JACS 87, 2443 (1965).

48. N. S. Bayliss, J. Chem. Phys. 18, 292 (1950).

49. S. Fery-Forgues, M. T. Le Bris, J. P. Guetté and B. Valeur, J. Phys. Chem. 92, 6233 (1988).

50. A. Declémy, C. Rullière and B. Valeur (private communication).

51. K. Itoh and T. Azumi, Chem. Phys. Lett. 22, 395 (1973).

52. K. Itoh and T. Azumi, J. Chem. Phys. 62, 3431 (1975).

53. S. Marguet and J. C. Mialocq (to be published).

54. D. N. Dempster, T. Morrow, R. Rankin and G. F. Thompson, J. C. S. Farad. II, 68, 1479 (1972).

55. M. Arvis and J. C. Mialocq, J. C. S. Farad. II, 75, 415 (1979).

56. D. Doizi and J. C. Mialocq, J. Phys. Chem. 91, 3524 (1987).

57. F. P. Schäfer, Dye Lasers (Topics in Appl. Phys. Vol. 1, Springer Verlag., Berlin, 1977), 2nd ed., Chap. 1, p. 32.

58. K. H. Drexhage, Dye Lasers (Topics in Appl. Phys. Vol. 1, Springer Verlag, Berlin, 1977) 2nd ed., Chap. 4, p. 161.

59. Y. B. Sheck, N. P. Kovalenko and M. V. Alfimov, J. Luminesc. 15, 157 (1977).

60. E. Haas, G. Fischer and E. Fischer, J. Phys. Chem. 82, 1638 (1978).

61. J. B. Birks, G. Bartocci, G. G. Aloisi, S. Dellonte and F. Barigelletti, Chem. Phys. 51, 113 (1980).

62. G. Fischer and E. Fischer, J. Phys. Chem. 85, 2611 (1981).

63. E. Fischer, J. Photochem. 17, 331 (1981).

64. K. P. Ghiggino, P. F. Skilton and E. Fischer, JACS 108, 1146 (1986).

65. J. Pouget and B. Valeur (unpublished results). 